European Journal of Training and Development Studies

Vol.9 No.1, pp.1-12, 2022

Print ISSN: 2057-5238(Print),

Online ISSN: 2057-5246(Online)

\title{
PSYCHOLOGICAL VARIABLES AS DETERMINANTS OF SUICIDE BEHAVIOUR AMONG ADOLESCENTS IN RIVERS STATE, NIGERIA.
}

\author{
Essien, B.S. \\ Department of Educational Psychology, Guidance and Counselling, Faculty of Education \\ University of Port Harcourt \\ Dr. Agbakwuru, C. \\ Department of Educational Psychology, Guidance and Counselling,, Faculty of Education \\ University of Port Harcourt
}

\begin{abstract}
This study investigated some psychological variables as determinants of suicide behaviour among adolescents in Rivers State, Nigeria. It adopted the correlational research design. The population of the study was the entire 785 students of the three federal government colleges in Rivers State who exhibited suicide behaviour. Using purposive sampling, these students who exhibited suicide behaviour were drawn and used for the study. Three research questions and three hypotheses were tested at 0.05 level of significant. Two instrument namely suicide behaviour questionnaire (SBQ-R) by Osman et al and determinants of suicide behaviour (DSBQ) were used for the study. The $S B Q-R$ was adapted and used to find out those that exhibited suicide behaviour while the DSBQ was a Likert type scale that contained two sections (A \& B). Section A contains instruction on how to respond to the questionnaire while section B contains 2 sub sections that contain items on depression and self-esteem which were the independent variables. Experts in measurement and evaluation validated the instrument while the reliability index for suicide behaviour was 0.85, 0.72 for depression and 0.82 for self-esteem using Cronbach via SPSS. Simple regression was used to answer research question 1 and 2 and the corresponding hypotheses while multiple regression was used to answer research question 3 and the corresponding hypothesis at 0.005 alpha level. Findings were that depression $(p=0.003<0.005)$, self-esteem $(p=0.000<0.005)$ and joint psychological variables $(p=0.000<0.005)$ relates significantly to suicide behaviour. Based on the findings it was recommended that professional counsellors should counsell adolescents on depression and self-esteem.
\end{abstract}

KEYWORDS: suicide behaviour, adolescent, depression and self-esteem

\section{INTRODUCTION}

Some decades ago it was very rare to read or hear stories about adults much less adolescents taking their own lives by means of suicide but today the reverse is the case. A month hardly goes by without the news report from around the world of adolescents attempting or committing suicide due to reasons like failed romantic relationship, being jilted, unemployment, failed course in the university, poor performance in academic work, misunderstanding with siblings or parents and 
European Journal of Training and Development Studies

Vol.9 No.1, pp.1-12, 2022

Print ISSN: 2057-5238(Print),

Online ISSN: 2057-5246(Online)

being bullied or teased cruelly by peers. As adults, mothers and fathers when we hear news of the death of an adolescent by suicide we are stunned, confused and very sad regardless of whether we knew the victim or not. Previously the researcher felt and thought that there is no reason whatsoever for a young promising youth from a good home whose parents are caring, loving, God fearing and provide for their children's need to take their own lives or attempt to do so. Now the researcher has realized that suicide among adolescents has nothing to do with the socioeconomic status of their parents, background, nationality, race, ethnicity or religion.

Suicide is the taking of one's life through various means like hanging, gunshot, poisoning, overdose of drugs etc. Every year millions of young people attempt to take their own lives while thousands succeed. The Center for Disease Control and prevention (CDC, 2020) defined suicide as the death caused by injuring oneself with the intent to die. This suggests that if an individual inflicts a wound on himself or herself with the intention of dying, it is suicide. For instance, a person that takes overdose of drugs, shots himself with a gun or drinks poison, wants to kill himself. Suicide is seen as a large and growing public health problem since it is the $10^{\text {th }}$ leading causes of death in the United States and responsible for more than 48,000 deaths in 2018 which is about one death every 11 minutes. (CDC, 2020).

Specifically, suicide behaviour encompasses any behaviour, including verbal cues, that suggests that individuals are thinking about suicide or intends to harm or kill themselves (Columba, 2007). This means that any life threatening thought or behaviour that an individual engages in so as to harm or kill himself or herself is called suicide behaviour. Miller in Ping (2013) sees suicidal behaviour as a series of behaviours more than the suicide alone. These behaviours are separate but often lap in terms of conditions based on severity levels and they are four in number: - suicidal ideation, suicide-related communication, suicide attempts and suicide. It is worthy to note that as the severity level of suicidal behaviour increase, so the probability of death increases and not all youth with suicidal behaviour experience them in sequence (Mazz in Ping,2013).

Suicide ideation is thinking about, planning or considering suicide; it is also known as suicidal thoughts. Although many individuals who think or plan to end their lives by suicide do not actually attempt suicide but it is considered a risk factor. It is reported that in 2014, 2.2 million persons in the U.S made suicidal plans and most of them were teenagers; also $3.7 \%$ of the adult U.S population aged 18 and above that is an estimated 8.3 million had suicidal thoughts in the previous year 2008-09 (Wikipedia, 2020). On the other hand, suicidal attempt is "a self-inflicted, potentially injurious behaviour with a nonfatal outcome for which there is evidence either explicit or implicit of intent to die" (Silverman et al. in Ping 2013). Attempted suicide has to do with an individual trying to kill himself or herself in various ways like ingesting of poisonous substances, hanging, jumping over bridges with the clear intent and expectation of death but due to one reason or the other, the person did not succeed in his intent. It is worthy to know that those who attempt suicide have an increased risk in suicide. Self-harm describes any behaviour or injury that is inflicted by oneself. This is usually done as a way to cope with distressing feelings and thoughts. The different methods used to self-harm are cutting, burning or non-lethal overdoses. Self-harm includes high 
European Journal of Training and Development Studies

Vol.9 No.1, pp.1-12, 2022

Print ISSN: 2057-5238(Print),

Online ISSN: 2057-5246(Online)

risk behaviours and any behaviour that causes injury irrespective of how minor the injury is (Mental Health Foundation, MHF,2020).

Adolescence is the period of transition between childhood and adulthood. It is a period whereby adolescents experience many changes including physical, sexual, cognitive, social and emotional. Their bodies and the way they relate to the world changes. There are three stages of adolescence and they are early adolescence (10-13), middle adolescence (Age 14-17) and later adolescence (Age 18-21 and beyond (Allen \& Waterman, 2019). Johan (2018) stated that adolescents are by nature vulnerable and have mental health problems because adolescent period is filled with changes and transitions from one state to another at the same time. He further went on to say that, during this period young ones are expected to make important decisions like career choice and peer-group. They are also faced with challenges like building new intimate relationships, developing self-esteem, building their own identity and responsibility and independence. Apart from these, externally they are confronted with high expectations from their parents and others which makes them feel helpless, insecure and a sense of losing control. It is observed that suicidal behaviour which includes thinking about killing oneself, planning suicide and attempting suicide often start in adolescence and is prevalent among them. Studies carried out in 2017 showed that there were 47 percent more suicides among people aged 15 to 19 than in the year 2000 and it is ranked as the second-leading cause of death with more than 6,200 students among people aged 1524 (Gretchen \& Gorena, 2019). Adolescent suicide and suicide behaviour is on the rise and this is particularly disturbing for a country like Nigeria because the youth makeup majority of the population. Olushola et al (2021) stated that, the rate of suicide in Nigeria is $17.3 / 100,000$ which is among the highest. Britt et al. (2015) stated that some of the factors that are associated with youth suicidal behaviours in low and middle income countries includes bullying, physical and sexual abuse, mental disorders, substance use, depressive symptoms, weak family and social relationships.

From these, it can be seen that suicide behaviour among adolescents is indeed a worldwide phenomenon and a pandemic that needs to be curbed or reduced. Suicide behaviour can affect anybody irrespective of their social-economic background, race, nationality and religion. However, there are factors that may lead to suicide behaviour among adolescents.

Depression is defined by the National institute of Mental Health (NIMH, 2020) as a common but serious mood disorder in which it's severe symptoms affect how an individual handle daily life like working, eating, sleeping, feeling and thinking. In the same vein, Mayo Clinic (2018) sees depression as a mood disorder that causes a persistent feeling of sadness and loss of interest that affects the way an individual feel, think and behave leading to emotional and physical problem. The symptom in teenagers may include eating or sleeping too much, self-harm, avoidance of social interaction, sadness, irritability, poor performance at school and feeling negative and worthless. There are different forms of depression and they are: Persistent depressive disorder, this usually occurs when an individual has a depressed mood that lasts for at least two years. An individual with persistent depressive disorder may have episodes of major depression along with periods of less severe symptoms. On the other hand, postpartum depression is experienced by women after 
European Journal of Training and Development Studies

Vol.9 No.1, pp.1-12, 2022

Print ISSN: 2057-5238(Print),

Online ISSN: 2057-5246(Online)

delivery. This result in feelings of anxiety, extreme sadness and exhaustion which makes it difficult for new mothers to care for themselves or their babies. Psychotic depression occurs when an individual has severe depression and a form of psychosis like hallucinations, having disturbing false fixed beliefs (delusions) while seasonal affective disorder occurs during less natural sunlight or winter months and individuals with seasonal affective disorder are withdrawn socially, sleep more and gain more weight but usually after winter they are okay till another winter.

These definitions explain depression as a constant feeling of hopelessness and despair that takes hold on an individual and refuses to go away; it affects the individual daily activities and make it extremely difficult for a person to get through the day. Smith, Robinson and Segal (2019) stated that some people describe depression as "living in a black hole" or having a feeling of impending doom while others feel lifeless, empty and apathetic. From the aforementioned of depression, it can be deduced that an individual with this mood disorder can entertain suicide behaviours.

Huyen et al (2020) studied the prevalence of suicidal behaviours and depression among adolescents in Hanoi Vietnam. The researchers used three high schools, two public and one private school. Multi stage cluster sampling techniques were employed. Two questionnaires were used for the study namely the youth risk behaviour surveillance (YRBS) and modified depression scale (MDS). The sample size was 661 high school students while the YRBS was used to measure six behaviours which are unintentional injuries and violence, tobacco use, alcohol and drug use, sexual behaviours, dietary behaviours and physical activity. The MDS was used to measure depression symptomatology within the past 30 days which inquires about frequency of six symptoms of depression including sadness, irritability, hopelessness, sleep disturbance, difficulty concentrating and eating problems. To analyze the data, descriptive and analytical statistics were done using stata 15 software (stata corporation) also ANOVA and chi-square tests were used to assess the existence of relationship between outcomes and demographic characteristics. The result showed that suicidal behaviour and depression are common problems among adolescents in Vietnam. Also finding showed that the prevalence of 12-month suicidal thoughts, suicide plans and suicide attempts were $14.2 \%, 5.5 \%$ and $3.0 \%$ respectively while depression score mean was $16.1+4.9$ among major predictors of suicidal ideation.

Findlay (2017) examined depression and suicidal ideation among Canadians between the ages of 15 to 24. The study was to find out detailed information about depression and suicidal ideation among young Canadians including their use of mental health support. The data was collected from the 2012 Canadian community health survey mental health (CCHS-MH) which was used to describe rates and experience of depression and suicidal ideation among Canadians aged 15 - 24 including psychosocial characteristics of those who had depression or reported suicide thoughts. The findings showed that $11 \%$ of Canadians between ages 15 - 24 had experience depression in their life time, $7 \%$ in the past year also approximately $14 \%$ reported having had suicidal thoughts in their lifetime $6 \%$ of them in the past year. And lifetime depression and suicidal thoughts were moderately correlated $(r=34 p<.001)$. In addition, psychosocial factors like negative social interactions and the lower perceived ability to deal with stress were associated with depression and suicidal thoughts, although these associations differed for males and females. 
Another factor that could influence suicide behaviours is low self-esteem. Self-esteem is an individual's attitude and overall evaluation of their own worth, or evaluation of given traits, position in a group, their own activities and relationship with others (McGee \& William in Minev, 2018). This explains the fact that self-esteem is how much value and acceptance a person place on himself or herself. It involves one's love for oneself. So if an individual within himself acknowledges that he is physically attractive, has skills and abilities that help him achieve his goals, has good communication skills, can maintain inter-personal relationship and he's physically fit and healthy, these will give him adequate self-confidence, poise and he will be decisive when making decision which in turn will translate to healthy self-esteem. In addition, Colman (2015) in the Oxford dictionary of psychology sees self-esteem as one's attitude towards one's self or opinion or evaluation of oneself. This can be high or low. So simply put, people with self-esteem believe in themselves, are proud of what they do and feel liked and accepted (D'Arcy, 2018). It is very important for an individual to have a positive self-esteem about himself or herself because it can affect all aspects of one's life. For instance, an individual with a healthy self-esteem feels positive about himself and life in general which in turn enables the person to deal better with life's challenges. On the other hand, a person with low self-esteem always sees himself or herself in a negative and critical light which makes it impossible for the person to be able to take on life's challenges. Low self-esteem also makes an individual hide away from social situations, avoid things that they find challenging and stop trying new things. The forgoing clearly shows that low self-esteem can lead to suicide behaviours.

Thompson (2010) undertook a study on the suicidal process and self-esteem in other to test the association between response to a self- esteem inventory and levels of suicidal behaviour as conceptualized in the notion of the suicide process. The population for the study was 227 university undergraduates and the severity of suicidal behaviour over the lifespan (death wishes ideation, plans and attempts) as well as a self-esteem inventory. The findings showed that a negative relationship was found between the level of suicidality and self-esteem. Also in nearly all the cases, from any particular level were contained in the cohort of individuals who had displayed suicidal behaviour at a less serious level. which suggests a possible progression through each of the stages of suicidal behaviour, with very few cases showing a level of suicidal behaviour that was not associated with a previous, less serious form and that early entry into the suicidal process may be indicated by low self-esteem.

Soto-Sanz et al (2019) investigated self-esteem and suicidal behaviour in youth using metaanalyses to examine the relationship between low self-esteem and suicide attempts in young people (12-26) using random- effects model (ES) and odds ratio (OR). Heterogeneity and sensitivity analyses were formed. 9 studies were included in the meta-analysis. The meta-analysis showed that youths with lower self-esteem were more likely to have future suicide attempts with the effect size (self-esteem as continuous variable) of $\mathrm{d}=.58$ (95\% CI=44-.73) and, for low self-esteem (categorical variable) an $\mathrm{OR}=1.99(95 \%) \mathrm{CI}=1.39-2.86$ : $\mathrm{p}<.001)$. It was concluded that a low level of self-esteem is a risk factor for suicide attempts in adolescents/ young adults. The present study is similar to the former due to the fact that one of its independent variable is self-esteem and the dependent variable is suicide behaviour. 
European Journal of Training and Development Studies

Vol.9 No.1, pp.1-12, 2022

Print ISSN: 2057-5238(Print),

Online ISSN: 2057-5246(Online)

Unfortunately, there is an apparent lack of research reports in Rivers State, Nigeria that have investigated these psychological variables as they relate to suicide behaviour among in-school adolescents. A study of this nature is necessary because the results will form a basis for reasonable manipulation of these variables to mitigate the rising wave of suicide behaviour among adolescents in our society. This study was embarked on to fill this gap in knowledge. The problem of the study posed as a research question is "to what extent do psychological variables relate to suicide behaviour among in-school adolesents in Rivers State, Nigeria”.

\section{The objectives of the study are:}

1. Investigate the extent depression relates to suicide behaviour among in-school adolescents in Rivers State.

2. Assess the extent self-esteem relates to suicide behaviour among in-school adolescents in Rivers State.

3. Determine the extent psychological variables jointly relate to suicide behaviour among inschool adolescents in Rivers State.

\section{The following research questions guided the study.}

1.To what extent does depression relate to suicide behaviour among in-school adolescents in Rivers State?

2. What is the relationship between self-esteem and suicide behaviour among in-school adolescents in Rivers State?

3.To what extent does psychological variables jointly relate to suicide behaviour among in-school adolescents in Rivers State.

Three null hypotheses were also formulated to guide the study, they are:

1. There is no significant relationship between depression and suicide behaviour among inschool adolescents in Rivers State.

2. There is no significant relationship between low self-esteem and suicide behaviour among in-school adolescents in Rivers State.

3. There is no significant relationship between the joint psychological variables and suicide behaviour among in-school adolescents in Rivers State.

\section{METHODOLOGY}

The research design for this study is correctional design. According to Nwankwo (2016:73) correlational design involves "finding out the extent of relationship between two or more variables, and data from such variables are in ratio or interval scales (scores)". This is done in other to make it possible for the scores to be correlated.

The population of the study consisted of the 785 students of the three Federal Government Colleges in Rivers State. Who were identified as manifesting risk factors of suicide behaviour. This entire population was drawn as the sample hence the study was census. To identify those with suicide behaviour, the researchers administered the "Suicide Behaviour Questionnaire Revised" to all the 
European Journal of Training and Development Studies

Vol.9 No.1, pp.1-12, 2022

Print ISSN: 2057-5238(Print),

Online ISSN: 2057-5246(Online)

4965 students in the three Federal Government Colleges in Rivers State. The questionnaire contained 10 items designed to measure suicide behaviour. This means that the maximum score of the instrument was 20. In determining those with suicide behaviour, the total score was divided into two, so any student who scored 20 and above was considered to elicit suicide behaviour and any that scored less than 20 was considered not to elicit suicide behaviour. In FGGC Aboluoma 257 exhibited suicide behaviour, FGC Rumuokoro 242 and FGC Ahoada 286 totaling 785 which served as both the population and the sample size of the study.

Two instruments were used for the study. The first is a standardized instrument the Suicide Behaviours Questionnaire-Revised (SBQ-R) by Osman et al. It is a self-report questionnaire designed to identify risk factors for suicide in adolescents. It is a four item questionnaire that asks four constructs within suicidal behavior domain which are lifetime ideation and attempt, recent frequency of ideation, suicide threats and self-assessed likelihood of future suicidal behaviour. The researchers adapted the instrument and modified it to become 10 items It is rated on 4-point Likert type scale. The second instrument is named Determinants of Suicide Behaviour Questionnaire (DSBQ) which is a 4-point Likert type scale that contains two sections (A \& B). Section A contains demographic information and instructions on how to respond to the instrument while section $\mathrm{B}$ contains 2 sub sections that contains items designed to elicit responses from the respondents on depression and self-esteem.

The reliabilities of both SBQ-R and DSBQ were determined using Cronbach alpha. Thirty copies of each of the instrument were given to 30 in-school adolescents who were not part of the targeted sample but with similar characteristics. After their response, their scores were subjected to Cronbach via SPSS. A reliability index of 0.85 was realized for SBQ-R while DSBQ 0.72 was realized for depression and 0.82 for self-esteem

Simple regression analysis was used to analyzed research questions 1and 2 their corresponding hypotheses while multiple regression was used to answer research questions 3 and it corresponding hypothesis

\section{RESULTS}

Research Question One: To what extent does depression relate to suicide behaviour among inschool adolescents in Rivers State?

Table 1.1 Simple regression analysis showing $\mathrm{R}$ Correlations and $\mathrm{F}$ values for relationship between depression and suicide behaviour among in-school adolescents in Rivers State. The result of the analysis is presented in table $4: 1 \mathrm{a} \& \mathrm{~b}$.

\section{Table 1.1a}

Model R R Square

\begin{tabular}{l}
$.181^{\mathrm{a}} \quad .033$ \\
\hline 1 \\
@ECRTD-UK https://www.eajournals.org/ \\
URL: https://doi.org/10.37745/ejtds.2014
\end{tabular}

Adjusted R Square Std. Error of the Estimate

4.518 
European Journal of Training and Development Studies

Vol.9 No.1, pp.1-12, 2022

Print ISSN: 2057-5238(Print),

Online ISSN: 2057-5246(Online)

From the analysis in Table 1.1a, the relationship between depression and suicide behaviour is $0.181, \mathrm{R}^{2}$ value is 0.033 , The adjusted $\mathrm{R}^{2}$ value is 0.031 while the standard error of estimates is 4.518. Furthermore, the $\mathrm{R}^{2}$ value signifies that depression has a relationship of about $3.3 \%$ $(0.033 \times 100)$ with suicide behaviour expressed by adolescents in Rivers state.

Hypothesis One: There is no significant relationship between depression and suicide behaviour among in-school adolescents in Rivers State

Table 1.1b

\begin{tabular}{llllllll} 
Model & & $\begin{array}{l}\text { Sum } \\
\text { Squares }\end{array}$ & ofDf & $\begin{array}{l}\text { Mean } \\
\text { Square }\end{array}$ & F & Sig & Result \\
\hline \multirow{2}{*}{$\begin{array}{llllll}\text { Regression } \\
1\end{array}$} & 541.07 & 1 & 541.076 & 26.511 & 0.000 & $\begin{array}{l}\text { Significant } \\
\text { (Reject Ho) }\end{array}$ \\
& $\begin{array}{l}\text { Residual } \\
\text { Total }\end{array}$ & 16000.96 & 784 & 20.409 & & & \\
& 16542.03 & 785 & & & &
\end{tabular}

The calculated F value in Table $1.1 \mathrm{~b}$ is 26.511 while the Sig value is 0.000 . therefore, since the $\operatorname{Sig}(p=0.000<0.05)$ is less than the alpha of 0.05 at 784 degrees of freedom, the null hypothesis is rejected and the alternate retained meaning that actually there is a significant relationship between depression and suicide behaviour among in-school adolescents in Rivers State.

Research Question Two: To what extent does self-esteem relate to suicide behaviour among inschool adolescents in Rivers State?

Table 2.2a Simple regression analysis showing $R$ Correlations and $F$ values for relationship between self-esteem and suicide behaviour among in-school adolescents in Rivers State. The result of the analysis is presented in table $2: 2 \mathrm{a} \& \mathrm{~b}$

Table 2.2a

\begin{tabular}{llll} 
Model R Square Adjusted R Square & $\begin{array}{l}\text { Std. Error of the } \\
\text { Estimate }\end{array}$ \\
\hline
\end{tabular}

\begin{tabular}{lllll}
\hline 1 & $.077^{\mathrm{a}}$ & .006 & .005 & 4.580
\end{tabular}

The analysis in Table 2.2a shows that the relationship between self-esteem and suicide behaviour is $0.77, \mathrm{R}^{2}$ value is 0.006 , the adjusted $\mathrm{R}^{2}$ value is 0.005 while the standard error of estimates is 4.580. From the $\mathrm{R}^{2}$ value, there is an indication that self-esteem has a relationship of about $0.6 \%$ (0.006x 100) with suicide behaviour expressed by adolescents in Rivers state.

Hypothesis Two: There is no significant relationship between self-esteem and suicide behaviour among in-school adolescents in Rivers State. 
European Journal of Training and Development Studies

Vol.9 No.1, pp.1-12, 2022

Print ISSN: 2057-5238(Print),

Online ISSN: 2057-5246(Online)

Table 2.2b

\begin{tabular}{|c|c|c|c|c|c|c|c|}
\hline \multicolumn{2}{|l|}{ Model } & \multicolumn{2}{|l|}{$\begin{array}{l}\text { Sum } \\
\text { Squares }\end{array}$} & \multicolumn{2}{|c|}{ Mean Square F } & Sig & Result. \\
\hline \multirow{3}{*}{1} & Regression & 98.683 & 1 & 98.683 & 4.705 & 0.030 & $\begin{array}{l}\text { Significant } \\
\text { (Reject Ho) }\end{array}$ \\
\hline & Residual & 16443.354 & 784 & 20.974 & & & \\
\hline & Total & 16542.037 & 785 & & & & \\
\hline
\end{tabular}

The calculated F value in Table $2.2 \mathrm{~b}$ also is 4.705 while the Sig value is 0.03 . Hence, since the $\operatorname{Sig}(p=0.03<0.05)$ is less than the alpha of 0.05 at 784 degrees of freedom, the null hypothesis is rejected and the alternate retained meaning that there is a significant relationship between selfesteem and suicide behaviour among in-school adolescents in Rivers State.

Research Question Three: To what extent does psychological variables jointly relate to suicide behaviour among in-school adolescents in Rivers State?

Table 3.3a Multiple regression analysis showing $R$ Correlations and $F$ values for relationship between joint Psychological Variables and suicide behaviour among in-school adolescents in Rivers State. The result of the analysis is presented in table $4: 3 \mathrm{a} \& \mathrm{~b}$.

Table 3.3a: Multiple regression showing $R$ values

\begin{tabular}{lllll} 
Model & $\mathbf{R}$ & R Square & $\begin{array}{l}\text { Adjusted } \\
\text { Square }\end{array}$ & $\begin{array}{l}\text { RStd. Error of the } \\
\text { Estimate }\end{array}$ \\
\hline 1 & $.184^{\mathrm{a}}$ & .034 & .031 & 4.518 \\
\hline
\end{tabular}

The analysis in Table 3.3a shows that the joint relationship between psychological variables and suicide behaviour is $0.185, \mathrm{R}^{2}$ value is 0.034 , The adjusted $\mathrm{R}^{2}$ value is 0.031 while the standard error of estimates is 4.518 . From the $\mathrm{R}^{2}$ value, there is an indication that the joint psychological variables account for about $3.4 \%(0.034 \times 100)$ of suicide behaviour expressed by adolescents in Rivers state.

Hypothesis Three: There is no significant relationship between the joint psychological variables and suicide behaviour among in-school adolescents in Rivers State. 
European Journal of Training and Development Studies

Vol.9 No.1, pp.1-12, 2022

Print ISSN: 2057-5238(Print),

Online ISSN: 2057-5246(Online)

Table 3.3b: Showing F and Sig values of ANOVA Summary

\begin{tabular}{llllllll} 
Model & & $\begin{array}{l}\text { Sum } \\
\text { Squares }\end{array}$ & ofDf & Mean SquareF & Sig & Result \\
\hline \multirow{4}{*}{$\begin{array}{llllll}\text { Regression } \\
1\end{array}$} & 561.44 & 3 & 280.72 & 13.75 & 0.000 & $\begin{array}{l}\text { Significant } \\
\text { (Reject Ho) }\end{array}$ \\
& $\begin{array}{l}\text { Residual } \\
\text { Total }\end{array}$ & 15980.59 & 783 & 20.40 & & & \\
\hline
\end{tabular}

The calculated F value in Table $3.3 \mathrm{~b}$ is 13.75 while the Sig Value is 0.000 . Hence, since the $\operatorname{Sig}(\mathrm{p}=0.000<0.05)$ is less than the alpha of 0.05 at 783 degrees of freedom, the null hypothesis is rejected and the alternate retained meaning that there is a significant relationship between the joint psychological variables and suicide behaviour among in-school adolescents in Rivers State.

\section{DISCUSSION}

The findings of this study are discussed below based on the research questions and hypothesis. From the findings in table 1, it is revealed that depression has a significant relationship with suicide behaviour among adolescents in Rivers State. This finding means that adolescents may have a tendency to commit suicide or even involved in suicidal behaviour when they are depressed. The finding also means that depression is capable of making adolescents to contemplate suicide. It may also come because many adolescents have thought that the only way to get relieved of their depressive state or frustration is to engage in suicide related behaviours. This finding have thrown more light into the serious nature of depression. Generally, many adults including parents over the years might have be-little the tendency of depression occurring among adolescents. They might have also not realized the destructive effect that depression have caused in the lives of adolescents. On the other way round, they might have also attributed the effect of depression to other factors thereby undermining the power of it. This finding is not in any way surprising to the researcher because prior to this research, as an individual that is working with adolescents, she has observed a lot of suicide related behaviours which adolescents have engaged in and has over the years also observed that such adolescents have physical or visible symptoms of depression. The finding is also not surprising because serious or traumatic event in the life of adolescents can cause depression and in most cases, may lead to behaviours that are related to suicide. Over the years, suicidal behaviours have been used by adolescents to ward-off their depressive state. This finding is in line with the findings reported by Huyen et al (2020), Findlay (2017), who both reported findings in support of the present study that depression is related to suicide behaviour among individuals.

Findings from research question two have revealed that self-esteem has a significant relationship with suicide behaviour among adolescents in Rivers State. This finding means that the way adolescents carry himself or go about their businesses can have an effect on whether they engage in suicide behaviour or not. The researcher had defined self-esteem to be the way an individual think about himself and also suicide behaviours include all those behaviours that are capable of 
European Journal of Training and Development Studies

Vol.9 No.1, pp.1-12, 2022

Print ISSN: 2057-5238(Print),

Online ISSN: 2057-5246(Online)

harming individuals. The finding means that adolescents who think lowly of themselves may experience or engage in suicide behaviours. From this premise, it could be that if adolescent have a low self-esteem, if they see themselves poorly, it may make them to be involved in suicide behaviour. On the contrary, it could also be that adolescents who esteem themselves very high may also get involved in suicide behaviour. for instance, it could be that adolescent with high selfesteem who lives highly and who act as if they are more superior to others may likely get involved in suicide behaviours when they perceive that they are incapable of living up to the standard they have set for themselves. Also it is likely that when adolescents extol themselves highly, they may be involved in reckless behaviours like drinking, clubbing high-speed activities and so on and so forth, this behaviours can only be attributed or related to their self-esteem. as noted earlier low self-esteem could be related to lowly feeling as well as depression which can lead individuals to contemplate suicide. It could also be those who esteem themselves highly may also engage in dangerous and adventurous behaviours which they may not be aware are suicidal. The finding of the study is expected by the researcher because series of reviews made by other researchers have pointed towards the fact that self-esteem is related significantly or insignificantly to suicide behaviours among individuals and especially adolescents. The findings of Thomson (2020) and Soto-sanz et al (2019) both reported findings similar to the present one. In conclusion, while suicide behaviour is real, adolescents can overcome suicide behaviour if they are aware of the dangers of depression and improve their self-esteem.

\section{Recommendation}

1.More awareness campaign should be made on the dangers associated with adolescent depression using the mass media

2.Parents and teachers most especially should be mindful of the way they speak to adolescents in their care so as not to undermine their self-esteem.

\section{REFRENCES}

Allen, B., \& Waterman, H. (2019). Stages of adolescent. www.Healthychildren. org> Pages

Britt, M., Genvieve, G., Mariane, S. \& Frank, J.E. (2016). Adolescent suicide behaviour in 32 low and middle-income countries. Bulletin of the World Health Organization 2016, 94,340-35. http://dx.doi.org/102471/BLT.15/163295

Centers of Disease Control and Prevention (2020). Preventing suicide / violence prevention injury center / CDC ww.cdc.gov>suicide>fastfact.world health organization suicide www.who.int $>$.. $>$ Detail

Colin, M. (2015). Cambridge advance learner's dictionary

Columba, M. (2007). Suicide - Related Behaviour - understanding. Caring and therapeutic responses pest Sussex. John Wiley \& sons, Ltd

D' Arcy, L. (2018). How can I improve myself - Esteem for teens) - Nemours kidsHealth. https://kidshealth.org>teens> anxiety

Findlay, L. (2017) Depression and suicidal ideation among Canadians aged 15 to 24. Statistics Canada, catalogue no 82 - 003x.Health Report. 28(1), 3 - 11.

Gretehen, F., \& Gorena, M. (2019). Suicide among teens and young adults reaches highest 
European Journal of Training and Development Studies

Vol.9 No.1, pp.1-12, 2022

Print ISSN: 2057-5238(Print),

Online ISSN: 2057-5246(Online)

Level since 2000/PBS...www.pbs.org>nation>suicide...... PBS NEWsHour

9/10/2020 1:10pm

Huyen, N.T.K., Luong, N.T. \& Anh, L.T.K (2021). Suicidal behaviour and depression "among adolescents in Hanio, Vietnam: A multilevel analysis of data from the Youth Risk Behaviour Survey 2019. Health psychol open.2020 Jul-Dec; 7(2) doi:10.1177/2055102920954711 https//www.ncbi.nlm.nih.gov>pmc

Olushola, O., Bolanle, O., \& Akintayo, O. (2021). Trents and patterns of suicide beahaviour in Nigeria: Mixed methods analysis of the media reports from 2016 to 2019. South African Journal of Psychiatry https//www.ncbi.nlm.nih.gov>pmc

Johan, B. (2020). Suicide and youth: Risk factors www.ncbi.nlm.nih.gov Mental Health Foundation (2020). The truth about self-harm.www.mentalhealth.org.uk> Truth_ab.

Mayo Clinic (2018). Depression (major depression order)- symptoms and causes www.mayoclinic.org>syc-20356007

Minev, M. (2018). Self - Esteem and Depression in Adolescents.Trakia Journal of Sciences, 3(2), 119 - 127. http://www.uni- sz.bgdoi: 10 .155477 .tjs. 2018. 02.008

Ping, G. (2013). Bullying, Depression, and suicidal behaviours in Adolescents: secondary Analysis of youth Behaviour survey Data. A thesis submitted to the faculty of the university of Philadelphia college of osteopathic Medicine Psychology dissertation. Paper 360

Soto-Sanz,V., Piqueras, J.A., Rodriguez-Marin, J. \& Perez-Vazquez, M.( 2019). Self-esteem and suicide behaviour in youth: A meta-analysis of longitudinal studies. Pubmed.gov psicothema.2019 aug;31(3):246254. dio:10.7334

Thompson, A.H. (2010). The suicidal process and self-esteem. Crisis: The Journal of Crisis Intervention and Suicide Prevention, 31(6), 311-316. https://doi.org/10.1027/0227 -5910/ a000045

Wikipedia (2020). Suicidal ideation-en.mwikipedia,org>wiki>suicida... 